\title{
Changes in flow regimes of the Yellow River in the Headwater Area of the Yellow River on the northeastern Qinghai-Tibet Plateau, SW China during 1955-2040
}

\author{
Qiang $\mathrm{Ma}^{1}$, Huijun $\mathrm{Jin}^{2}$, Sihai Liang ${ }^{3}$, Victor Bense ${ }^{4}$, and yongchao lan $^{5}$ \\ ${ }^{1}$ Northwest Institute of Eco-Environment and Resources \\ ${ }^{2}$ Cold and Arid Regions Environmental and Engineering Research Institute, Chinese \\ Academy of Sciences \\ ${ }^{3}$ China University of Geosciences Beijing \\ ${ }^{4}$ Wageningen Universtiy \\ ${ }^{5}$ Chinese Academy of Sciences
}

November 16, 2020

\begin{abstract}
Human disturbance has substantially altered real-time flow regimes. The Headwater Area of the Yellow River (HAYR, above Huanghe'yan Hydrological Station) on the northeastern Qinghai-Tibet Plateau, Southwest China has been undergoing extensively streamflow changes, permafrost degradation and ecological deterioration under a warming climate. However, the damming of the Yellow River complicates examining the relations between hydroclimatic variables and streamflow dynamics. In this study, monthly streamflow of the Yellow River (YR) at the Huanghe'yan Hydrological Station is reconstructed for 1955-2019 dusing the double mass curve (DMC) method and then forecasted for the next 20 years (2020-2040) using Elman Neural Network (ENN) time-series method. Construction of dam (1998-2000) has caused a reduction of 53.5\%-68.4\% in annual streamflow and a reduction of $71.8 \%$-94.4\% in annual streamflow of dry years (2003-2005) in the HAYR and recent dam removal (September 2018) has boosted annual streamflow by $123 \%-210 \%$ (2018-2019). Post-correction trends of annual maximum (QMax) and minimum (QMin) streamflows and the ratio of the QMax/QMin of the YR in the HAYR (0.18 and 0.03 m3?s?1?yr?1 and -0.04 yr?1) compared to those of pre-correction values $(-0.25,-0.004 \mathrm{~m} 3$ ?s?1?yr?1 and $0.001 \mathrm{yr}$ ? $)$ have revealed hydrological impacts of degrading permafrost. Based on the ENN model predictions, over the next 20 years, the increasing trend of the YR flow in the HAYR would generally be accelerated at a rate of $0.42 \mathrm{~m} 3$ ?s?1?yr?1. Boosting rates of spring (0.57 m3?s?1?yr?1) and autumn (0.18 m3?s?1?yr?1) YR flow would see an advance of snow-melt season and delayed arrival of winter. This suggests an elongating growing season, which indicates ameliorating phonological and soil nutrient and hydrothermal environments for vegetation in the HAYR. These hydrological and ecological change trends in the HAYR may potentially improve ecological safety and water supplies security in the HAYR and downstream YR basins.
\end{abstract}

\section{Changes in flow regimes of the Yellow River in the Headwater Area of the Yellow River on the northeastern Qinghai-Tibet Plateau, SW China during 1955-2040}

Qiang $\mathrm{Ma}^{1}$, Huijun Jin ${ }^{1,2}{ }^{*}$, Sihai Liang ${ }^{4}$, Victor F. Bense ${ }^{3,5}$, Yongchao Lan ${ }^{1}$

1. State Key Laboratory of Frozen Soils Engineering, Northwest Institute of Eco-Environment and Resources, Chinese Academy of Sciences, Lanzhou 730000, China;

2. Northeast-China Observatory and Research-Station of Permafrost Geo-Environment-Ministry of Education, Institute of Cold-Regions Engineering Science and Technology, and School of Civil Engineering, Northeast Forestry University, Harbin 150040, China; 
3. School of Water Resources and Environment, China University of Geosciences, Beijing100083, China;

4. Hydrology and Quantitative Water Management Group, Department of Environmental Sciences, Wageningen University, Wageningen 6708PB, The Netherlands, and;

Correspondent author: H Jin at hjjin@lzb.ac.cnAbstract Human disturbance has substantially altered real-time flow regimes. The Headwater Area of the Yellow River (HAYR, above Huanghe'yan Hydrological Station) on the northeastern Qinghai-Tibet Plateau, Southwest China has been undergoing extensively streamflow changes, permafrost degradation and ecological deterioration under a warming climate. However, the damming of the Yellow River complicates examining the relations between hydroclimatic variables and streamflow dynamics. In this study, monthly streamflow of the Yellow River (YR) at the Huanghe'yan Hydrological Station is reconstructed for 1955-2019 dusing the double mass curve (DMC) method and then forecasted for the next 20 years (2020-2040) using Elman Neural Network (ENN) time-series method. Construction of dam (1998-2000) has caused a reduction of 53.5\%-68.4\% in annual streamflow and a reduction of $71.8 \%-94.4 \%$ in annual streamflow of dry years (2003-2005) in the HAYR and recent dam removal (September 2018) has boosted annual streamflow by $123 \%-210 \%$ (2018-2019). Post-correction trends of annual maximum $\left(\mathrm{Q}_{\mathrm{Max}}\right)$ and minimum $\left(\mathrm{Q}_{\mathrm{Min}}\right)$ streamflows and the ratio of the $\mathrm{Q}_{\mathrm{Max}} / \mathrm{Q}_{\mathrm{Min}}$ of the $\mathrm{YR}$ in the HAYR $\left(0.18\right.$ and $0.03 \mathrm{~m}^{3}[?] \mathrm{s}^{-1}[?] \mathrm{yr}^{-1}$ and $\left.-0.04 \mathrm{yr}^{-1}\right)$ compared to those of pre-correction values $(-0.25,-0.004$ $\mathrm{m}^{3}[?] \mathrm{s}^{-1}[?] \mathrm{yr}^{-1}$ and $\left.0.001 \mathrm{yr}^{-1}\right)$ have revealed hydrological impacts of degrading permafrost. Based on the ENN model predictions, over the next 20 years, the increasing trend of the YR flow in the HAYR would generally be accelerated at a rate of $0.42 \mathrm{~m}^{3}[?] \mathrm{s}^{-1}[?] \mathrm{yr}^{-1}$. Boosting rates of spring $\left(0.57 \mathrm{~m}^{3}[?] \mathrm{s}^{-1}[?] \mathrm{yr}^{-1}\right)$ and autumn $\left(0.18 \mathrm{~m}^{3}[?] \mathrm{s}^{-1}[?] \mathrm{yr}^{-1}\right)$ YR flow would see an advance of snow-melt season and delayed arrival of winter. This suggests an elongating growing season, which indicates ameliorating phonological and soil nutrient and hydrothermal environments for vegetation in the HAYR. These hydrological and ecological change trends in the HAYR may potentially improve ecological safety and water supplies security in the HAYR and downstream YR basins.Key words: Warming climate; streamflow data correction for damming; streamflow forecasting; Artificial Neural Network time-series method; Headwater area of Yellow River

\section{Introduction}

Anthropogenic activities (e.g., river damming) can substantially change streamflow regimes. Stuefer et al. (2011) noted that the annual average streamflow and the relationship between precipitation and streamflow could be greatly changed by damming issues. Adam et al. (2007) addressed the shifts in seasonal variability of streamflow closely related to dams. Chai et al. (2019) highlighted that, under the damming effects, the streamflow had a negative anomaly in flood seasons and a positive anomaly in draught seasons in comparison with those of the pre-damming period. As such, damming can change streamflow in both inter- and intraannual regimes.

Important shifts in streamflow regimes have been extensively reported in Arctic, boreal, alpine, and highplateau permafrost regions caused by permafrost degradation under a warming climate (e.g., Jin et al., 2009; Ge et al., 2013; Bring et al., 2017; Ma et al., 2019). Permafrost degradation will improve hydraulic connectivity between surface and subsurface waters (Jin et al., 2009, 2019; Cheng and Jin, 2012). A boosted streamflow and/or baseflow (e.g., Ge et al., 2013; Bring and Destouni, 2014; Haine et al., 2015; Kurylyk et al., 2016; Bring et al., 2017) and a decreased stormflow indicates an shifted intra-annual regimes of streamflow, such as flattened hydrographs and decreased ratio of annual maximum $/$ minimum streamflows $\left(\mathrm{Q}_{\mathrm{Max}} / \mathrm{Q}_{\mathrm{Min}}\right)$ (e.g., Prowse et al., 2006; Ye et al., 2009, 2011, 2012; Ma et al., 2019). An increased baseflow and melting ground-ice would boost groundwater recharge and increase groundwater storage upon permafrost thaw (e.g., Cheng and Jin, 2012; Bense et al., 2012; Qiu, 2012; Kane et al., 2013; Han et al., 2016; Walvoord and Kurylyk, 2016; Xu et al., 2019).

With a catchment area of $2.1 \times 10^{4} \mathrm{~km}^{2}$, the Headwater Area of the Yellow River (HAYR, above the Huangheyan (HHY) Hydrological Station), located on the northeastern Qinghai-Tibet Plateau (QTP), with widespread discontinuous (86\%) permafrost (Li et al., 2016; Wang et al., 2018; Sheng et al., 2020), and under a persistently warming and slightly wetting climate, flow regimes of the Yellow River (YR) in the HAYR showed no general increasing trend; instead, the YR flow showed a general trend of decline during 
1955-2019, but the ratio of the $\mathrm{Q}_{\mathrm{Max}} / \mathrm{Q}_{\mathrm{Min}}$ streamflow demonstrated an slightly increasing trend under permafrost degradation, which is inconsistent with the observed streamflow shifts in other northern and elevational permafrost regions (e.g., Qiu, 2012; Ge et al., 2013; Kurylyk et al., 2016; Bring et al., 2017).

Eco-environmental deterioration in the HAYR during 1980s and 1990s has drawn intense and extensive attentions of the public, governments and academic communities due to the HAYR originate the Yellow River which has economic importance for China and preserves endemic alpine flora species and relatively intact alpine ecosystem (Liu et al., 2014). Hydrological and ecological regimes in the HAYR are important to the ecological safety and water supplies security of local communities and downstream YR basins (Li et al., 2015). Changes in streamflow are strongly associated with the changes in alpine vegetation. In high Canadian Arctic regions, an $80 \%$ increase of vegetation productivity on the Banks Islands is documented and magnitude of greening is closely related to flow accumulation and soil moisture of the catchment (Campbell et al., 2020). Shiklomanov et al., (2013) addressed an increase trend in spring streamflow in Western Arctic Russia, which potentially indicates an advance of snow-melt season. By employing phenological parameters from Normalized Difference Vegetation Index (NDVI) time series, Zeng et al. (2013) confirmed this conclusion for an earlier start and longer length of the growing season in this region. Change in streamflow can be an indication of change in vegetation to some extent. Thus, reasonable understanding on changes in realtime streamflow in the HAYR is essential for examining their ecological implications. The future changes of YR streamflow in the HAYR plays important roles in ecological safety and freshwater budgets in local communities and downstream of the HAYR (Wang et al., 2019a). Thus, systematic analyses and explanations of the changes in streamflow in the HAYR would rely heavily on streamflow datasets and corrections of flow data resulting from anthropogenic disturbances deem very important.

In this paper, the historical YR streamflow in the HAYR was reconstructed by employing the double mass curve (DMC) method and streamflow data in neighboring downstream hydrological stations (Jimai, Maqu, and Tanag). Based on the reconstructed streamflow data in the HAYR, a future 20-year streamflow was predicted by using artificial neural networks (ANN) time-series prediction. Reconstructed streamflow dataset can serve as a fundamental dataset for permafrost hydrology, eco-hydrology and other related studies. Better predictions of streamflow patterns under shifting climate and environment can provide timely scientific support for ecological management and land-water resources at a watershed scale.

\section{Material and Methods}

\subsection{Study area}

The HAYR is a catchment of the Yellow River Basin above the Huanghe'yan (Yellow Riverside, HHY) Hydrological Station $\left(33.9^{\circ}-35.5^{\circ} \mathrm{N}, 95.8^{\circ}-98.4^{\circ} \mathrm{E} ; 4207-5245 \mathrm{~m}\right.$ a. s. 1.), with a catchment area of $2.1 \times 10^{4}$ $\mathrm{km}^{2}$ (Fig. 1). The HAYR is a typical high-elevation intermontane basin surrounded by very high mountains. To the north, the HAYR is bordered by the Buqing and Bur Hanbuda mountains; to the south and west, by the Baryan Har and Geshigeya mountains, respectively (Jin et al., 2009). In the intermontane river basins, landscape is basically flat or gently sloping; stream channels are largely braided on slopes or meandering in lowlands or valley wetlands.

YR streamflow at the HHY accounts for $2.75 \%$ of the multi-year average of annual streamflow (at Lijin hydrological station in Shandong Province, East China) of the YR to the Pacific Ocean (Ministry of Water Resources of the People's Republic of China (MWRPRC), 2008-2017) and area of the HAYR accounts for $2.79 \%$ to that of the YR Basin $\left(7.5 \times 10^{5} \mathrm{~km}^{2}\right)$. In January 1998, the First HAYR Hydropower Station (FHHS) or the Ngöring Lake Reservoir (Fig. 1) started to be built $30 \mathrm{~km}$ upstream the HHY for supplying electricity for the Madoi County-town (Machali town), Qinghai Province and the inundated area of the FHHS or Ngöring Lake Reservoir reached c.a. $16.5 \mathrm{~km}^{2}$. Presence of the FHHS or Ngöring Lake Reservoir have substantially altered spatiotemporal patterns of the YR streamflow as measured at the HHY. 


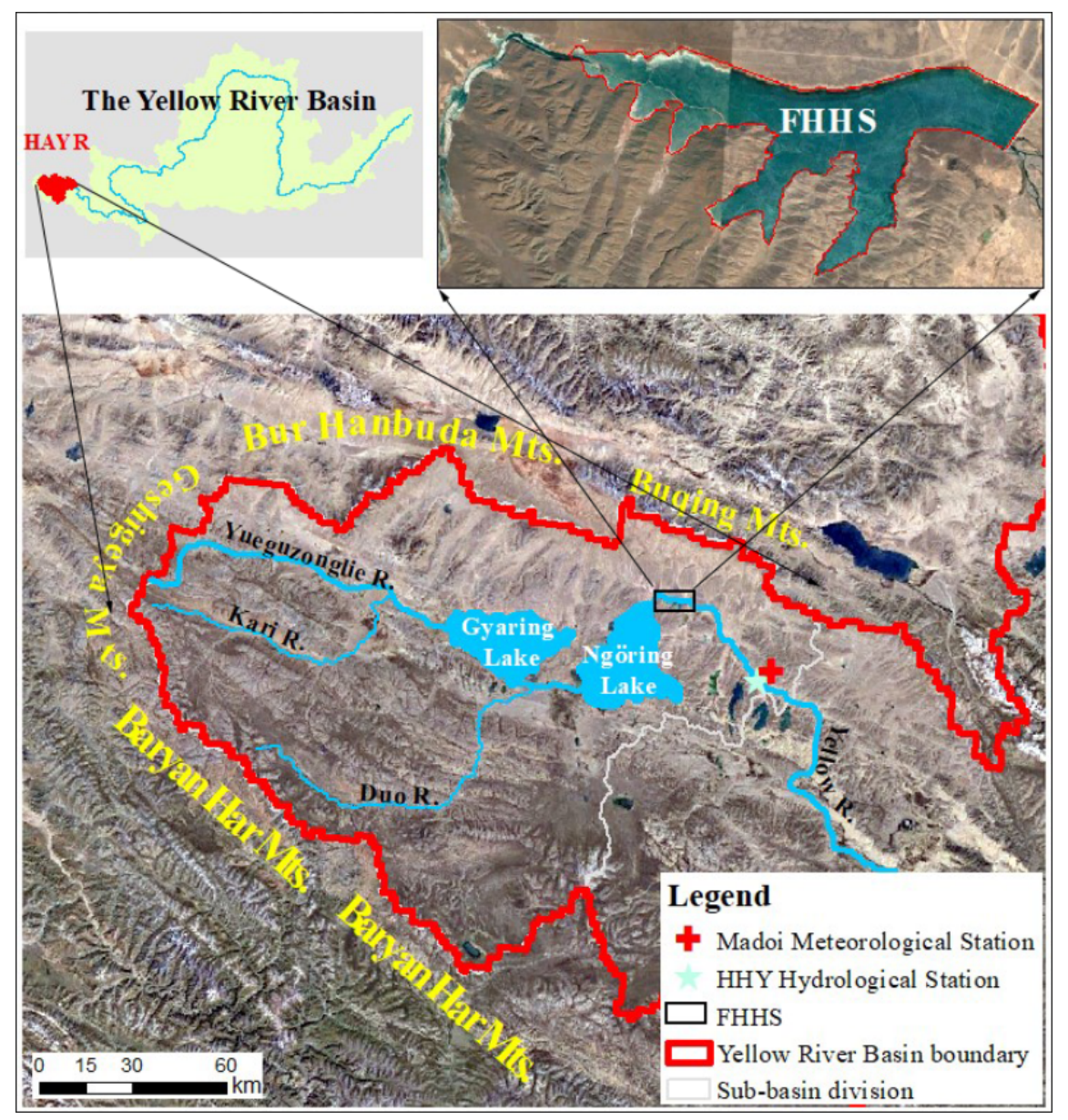

Fig. 1 Study sites, stations and catchment of the Headwater Area of the Yellow River (HAYR) on the northeastern Qinghai-Tibet Plateau in Southwest China (Base map was downloaded from Google maps)

The HAYR is dominated by a dry alpine climate under the control of alternating monsoons and westerlies. Mean annual air temperature ranged from -4.4 to -0.7 , with a multi-year average of mean annual air temperature at -1.7, and; annual precipitation was 484-755 $\mathrm{mm}$ (corrected for dynamic and other losses), with a multi-year average at $623.0 \mathrm{~mm}$, based on data series at the Madoi Meteorological Station from 1961-2017 (Ma et al., 2019).

In the HAYR, discontinuous, isolated, and sporadic permafrost presents and account for $86 \%$ of the catchment area above HHY near Madoi (Li et al., 2016; Wang et al., 2018; Sheng et al., 2020). Mean annual ground temperatures, generally measured at 10-25 $\mathrm{m}$ in depth, are higher than -2.0 ; permafrost thickness in the HAYR is generally less than $73 \mathrm{~m}$ according to borehole measurements (Luo et al., 2012), and; the average active layer thickness (ALT) in the HAYR varies from 1.8 - $2.4 \mathrm{~m}$ (1980-2006) (Luo et al., 2014). Ice-rich permafrost is widely distributed in lacustrine-marshland and alluvial-lacustrine plains and concentrated at depths of 3.0-10.0 $\mathrm{m}$ in the HAYR (Wang et al., 2018). In recent decades, the HAYR has witnessed a marked climate warming and subsequent permafrost degradation (Jin et al., 2009, 2011; Luo et al., 2018). The ALT has increased at a rate of $1.2 \mathrm{~cm} \mathrm{yr}^{-1}(1972-2012)$, and; by 2100, the ALT is projected to increase by 2.78-4.39 $\mathrm{m}$ and permafrost areal extent in the HAYR is projected to decrease by $7.5 \%-8.6 \%$ under varied carbon emission scenarios (Sheng et al., 2020).

Alpine steppes and meadow are widespread and soil types are dominated by Cryic Calcic Aridisols (Alpine 
steppe soil) and Mattic Cryic Cambisols (Alpine meadow soil) in the HAYR (Wang et al., 2007). Alpine steppes species is principally dominated by Stipa purpurea, Agropyron cristatum, Saussurea arenaria, etc., and alpine meadow species by Kobresia capillifolia, Kobresia humilis, Poa alpine, Saussurea pseudomalitiosa, and others (Qinghai Institute of Geological Survey (QIGS), 2000). Brierley et al. (2016) highlighted that a significant deterioration of alpine grasslands in the HAYR have been occurred in 1980s and 1990s, probably due to diminishing near-surface soil moisture contents.

\subsection{Data acquisition}

Monthly streamflow data are collected from the Yellow River Conservancy Commission (YRCC) for the Huanghe'yan and neighboring downstream hydrological stations (Jimai, Maqu and Tanag) from January 1955 to August 2019. During the period of August 1968 - December 1975, the Huanghe'yan Hydrological Station was moved $550 \mathrm{~m}$ downstreams and was rebuilt at the current location when hydrometric data during these periods at the Huanghe'yan Hydrological Station were absent. The missing observation at the Huanghe'yan Hydrological Station during these periods is interpolated using monthly streamflow data of downstream hydrological station of Maqu from January 1976 to December 1997 when the FHHS has not yet been built by double mass curve method.

Areal extent of permafrost is integrated from in-situ borehole data and extraction from distribution of permafrost on the QTP, which is a combination of existing permafrost maps compiling from multi-source data, such as literature, field investigation, in-situ borehole data, aerial photographs, and satellite images (Wang et al., 2018; Zheng et al., 2019; Luo et al., 2020).

\subsection{Methods}

Multiple methods are capable of reconstructing streamflow. By using stepwise regression analysis, Yang et al. (2004) reconstructed monthly streamflow at the outlet of the Yenisei Basin in Siberia Arctic, Russia. By employing hydrograph routing model, Stuefer et al. (2011) again reconstructed annual streamflow of the Yenisei Basin. By using variation of Hirsch's maintenance of variance extension method, Hernández-Henríquez et al. (2010) re-built monthly streamflow of the La Grande Riviére in northwestern Québec, Canada. Zhao et al. (2015) created a statistical model between annual river discharge and annual precipitation, and; using this model, the annual streamflow in the Yellow River Basin was reconstructed. While current streamflow reconstructions require as much as hydrometeorological data to create a statistical regressive model, the double mass curve (DMC) method only requires a single hydrometric data without/with minimal human disturbances, which is generally conducted for remote catchments with scarce data (Searcy et al., 1960).

The DMC is for detecting the consistency of streamflow, precipitation or riverine sediment data between stations in a given area (Searcy et al., 1960). It can be used to adjust or correct the inconsistent data. Data collected from two stations in an area with same time series and steps are reformatted by cumulating data ahead of this data in a time sequence. The reformatted data are set as X- and Y-axis, respectively. The graph with reformatted data is presented as a straight line as long as the relation between the two variables is a fixed ratio. When the condition of one of these variables change, such as changes in the method of data collection, or physical changes that may affect the mutual relations between or among variables, the straight line will be curved or defected. With similar geographical characteristics (i.e., vegetation, permafrost, and topography, among others), Zhang et al. (2004) found a close relationship of streamflow regimes between a hydrological station in the HAYR (Huanghe'yan Hydrological Station) and its neighboring hydrological stations in YR of the Source Area of Yellow River (above the Tanag Hydrological Station). Thus, the DMC can be applied to fill the unavailable measurements and correct the YR streamflow data in the HAYR.

Correction of the YR flow in the HAYR can help obtain the real-time streamflow, according to which, the YR flow in the HAYR can be furtherly predicted by using proper hydrological model or statistical model. Streamflow data display a complicated nonlinear pattern and are regulated by multiple factors (e.g., temperature, precipitation, evaporation, and basin physical conditions, among others). Forecasting of streamflow requires either process-based physical modeling or complex nonlinear statistical relationships. Physical models need a large amount of data and many parameters. Artificial neural network (ANN) can create complex 
nonlinear mapping and can be adapted for detecting subtle changes in the hydroclimatic environment, and thus it can be used for solving nonlinear problems (Birkundavyi et al., 2002) (Fig. 2). The ANN has been widely used in streamflow prediction (Dolling and Varas, 2002; Sahoo et al., 2019; Sequoira and Luna, 2019).

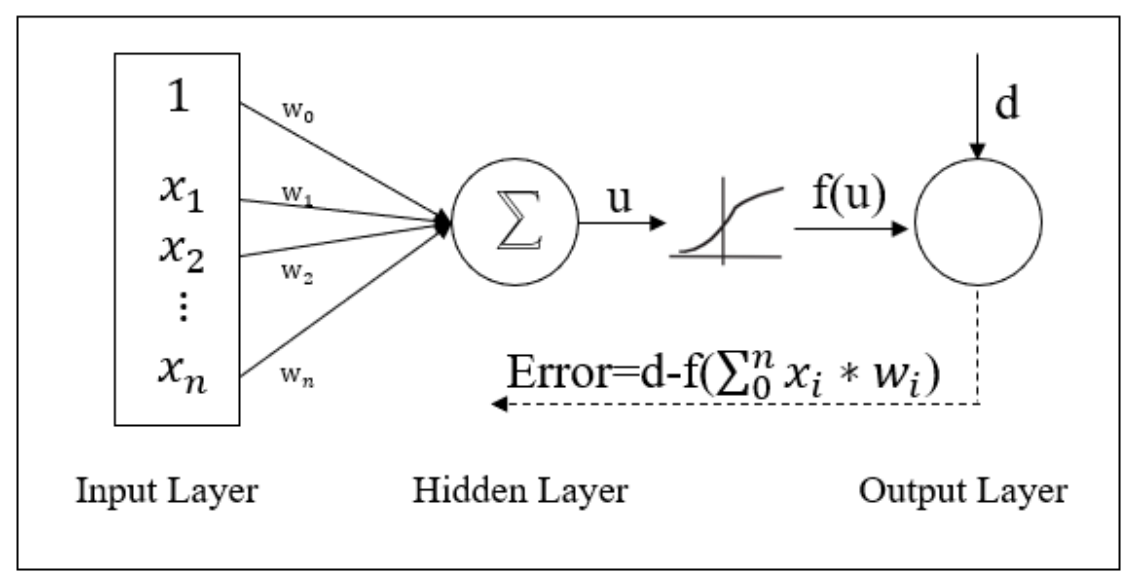

Fig. 2 General layout of artificial neural network_ single neuron case (adopted from Hu and Hwang $(2002))$

Note: The input labeled with a constant 1 represents the bias term used to model the threshold. The $\mathrm{w}_{\mathrm{i}}$ is synaptic weight; The input layer can be expressed as $\sum_{0}^{n} \mathbf{x}_{\mathbf{i}} * \mathbf{w}_{\mathbf{i}}$. In a hidden layer, multiple neurons and number of layers can be set to nonlinearly improve the network. The output $f(u)$ is compared with the desired target value d, and Error is computed by the difference between $\mathrm{f}(\mathrm{u})$ and $\mathrm{d}$. Error is minimized to derive the optimized weights $\mathrm{w}_{0}, \mathrm{w}_{1}, \ldots$, and $\mathrm{w}_{\mathrm{n}}$. A well-trained artificial network can be employed to forecast.

This work employs Elman network (Eqs. 1 and 2) to predict monthly streamflow conducted in MATLAB 2018a.

\begin{tabular}{ll}
\hline$y(t)=f(y(t-1), y(t-2), \ldots y(t-p))$ & $(1)$ \\
\hline$X=(y(t-1), y(t-2), \ldots, y(t-p))$ & $(2)$ \\
$\mathrm{D}=\iint\|y(t)-f(X)\|^{2} P(X, y(t)) d X d y(t)$ & $(3)$ \\
\hline
\end{tabular}

where $\mathrm{y}(\mathrm{t})$ is the observation of signal at time $\mathrm{t}$, and $\mathrm{y}(\mathrm{t}-1), \mathrm{y}(\mathrm{t}-2) \ldots, \mathrm{y}(\mathrm{t}-\mathrm{p})$ are previous observations of signal $\mathrm{y}(\mathrm{t}) \cdot f(X)$ is the neural network with minimized prediction residual.

Predictions are conducted as following steps:

\section{Reformat monthly streamflow data}

The array of 776 monthly streamflow data collected at HHY was reformatted into a matrix with 12 rows and 765 columns. The first to the $12^{\text {th }}$ data in 776 monthly streamflow data are set as the first column of the reformatted matrix; the second to $13^{\text {th }}$ data are in the second column, .... As such, there are a total of 765 columns in the matrix. The first 11 rows of the matrix are set as input of neural network $(y(t-1), y(t-2)$, $\cdots \cdots, \mathrm{y}(\mathrm{t}-11))$ and the last row, the output $(\mathrm{y}(\mathrm{t}))$. The length of the reformatted dataset is 765 .

\section{Network creation}

The reformatted matrix is divided into training data ( 1 to 500) and validating data (501 to 765). The created Elman neural network (ENN) train time-series data are used for validating the data. If the validated result 
is not well-fitted, redo the step 1 until the neural network is well fitted.

\section{3) Streamflow forecasting}

Using trained ENN to make streamflow data one month ahead. Then, the last 10 monthly streamflow data of the array of 776 monthly streamflow data together with the predicted one-month streamflow were inputted for predicting one other-month streamflow. This operation can be iterated until the next 20-year monthly streamflow is thus forecasted.

\section{Results and discussions}

\subsection{Reconstruction of streamflow records}

The FHHS was started to build in January 1998. At the beginning, stream channel was fully blocked with sandbags upstream the working plot (dam-site), inducing a sharply decreased streamflow as measured at the HHY. By January 2007, the FHHS had experienced building (January 1998-February 2000), impounding (March 2000-December 2002), and partial operation (January 2003-June 2005) due to the persistent low-flow periods in the HAYR. During the period of partial operation (not all water is preserved), the YR streamflow in the HAYR was mostly preserved in the reservoir. In 2007, precipitation markedly increased in the HAYR, resulting in a rising YR streamflow. The income water is largely discharged by outflowing from the reservoir due to its limited storage capacity. Thus, the gauged YR streamflow at the HHY largely represented the real-time streamflow.

In October 2016, the FHHS was abandoned again. The State Grid started to supply electricity for Madoi. Subsequently, the water gate of the FHHS was left partly open and the incoming water was largely reserved within the FHHS again. In September 2018, the removal of the FHHS was implemented for ecological restoration. Until August 2019, when streamflow data were most updated in this paper, the FHHS was kept open, but not completely removed.

The streamflow measured at the HHY was substantially disturbed by the presence of the FHHS, especially during 1998-2007, when the FHHS was under construction and trial operation for water impoundment, and during 2016-2019 when the FHHS was abandoned. The cumulative curve in Fig. 3 went much smoother than the original inclination during the period of October 2016 - September 2018. When the FHHS has been removed since September 2018, the YR streamflow at the HHY could be overestimated at the gauge of HHY due to outflowing water in the reservoir. The cumulative curve went sharply upwards during the period of October 2018-August 2019 (Fig. 3).

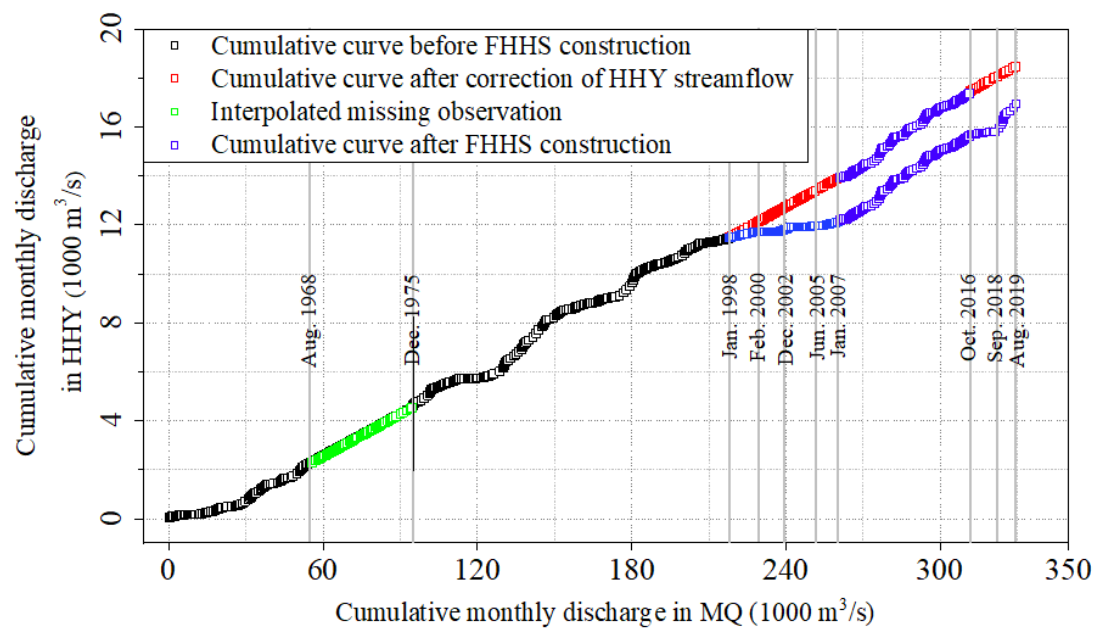

Fig. 3 Double mass curve (DMC) analysis between the Huanghe'yan (HHY) and Maqu (MQ) hydrological 
stations for correcting the Yellow River discharge at HHY near Madoi, Qinghai Province on the northeastern Qinghai-Tibet Plateau, Southwest China

Thus, in this study, the YR streamflow at the HHY was corrected for the periods from January 1998 to January 2007 and from October 2016 to August 2019 by employing the DMC method with data of undisturbed periods. A comparison of pre- and post-correction streamflows is shown in Fig. 4. During the active dam construction period (January 1998- February 2000), the gauged (uncorrected) YR streamflow in the HAYR as measured at HHY showed a reduction of $53.5 \%-68.4 \%$ in comparison with that of the corrected streamflow. During the period of March 2000-December 2002 when the FHHS was impounding water, the YR streamflow in the HAYR declined by $25.6 \%-95.1 \%$ in comparison with that of the corrected streamflow. During the dry periods (January 2003-June 2005), the YR streamflow in the HAYR showed a reduction of $71.8 \%-94.4 \%$ in comparison with that of the corrected streamflow. When the FHHS was abandoned during the period of October 2016-September 2018, the YR streamflow in the HAYR was once largely reserved within the FHHS and the measured flow rate was reduced by $74.2 \%$ in comparison with that of the post-correction. Recent dam removal of the FHHS (October 2018-August 2019) boosted YR streamflow in the HAYR by $123 \%-210 \%$ (2018-2019) in comparison with that of the post-correction. Thus, damming issues has largely changed annual streamflow in the HAYR.

Meanwhile, inter-annual trends of monthly, seasonal and annual streamflow of YR in the HAYR have also been substantially changed after streamflow correction. Pre-correction mean annual streamflow demonstrates generally decreasing trends $\left(-0.009 \mathrm{~m}^{3}[?] \mathrm{s}^{-1}[?] \mathrm{yr}^{-1}\right)$; it goes upwards $\left(0.11 \mathrm{~m}^{3}[?] \mathrm{s}^{-1}[?] \mathrm{yr}^{-1}\right)$ after streamflow correction. Hydrological season is divided in the HAYR, according to the monthly mean air temperature, precipitation and streamflow regimes, from November to next April as winter, May and June as spring, July and August as summer, and September and October as winter (Ma et al., 2019). Before correction of YR streamflow in the HAYR, spring, summer and autumn YR streamflow show decreasing trends of -0.04 , -0.18 and $-0.03 \mathrm{~m}^{3}[?] \mathrm{s}^{-1}[?] \mathrm{yr}^{-1}$, respectively, while the winter YR streamflow shows an increasing trend of 0.07 $\mathrm{m}^{3}[?] \mathrm{s}^{-1}[?] \mathrm{yr}^{-1}$. After correction, streamflow of YR in the HAYR in all four seasons (spring, summer, autumn and winter) shows consistently increasing trends $\left(0.16,0.12,0.16\right.$ and $0.08 \mathrm{~m}^{3}[?] \mathrm{s}^{-1}[?] \mathrm{yr}^{-1}$, respectively). Precorrection annual maximum and minimum YR streamflows and the ratio of the annual maximum $/ \mathrm{minimum}$ YR streamflows $\left(Q_{\max } / \mathrm{Q}_{\min }\right)$ show trends of -0.25 and $-0.004 \mathrm{~m}^{3}[?] \mathrm{s}^{-1}[?] \mathrm{yr}^{-1}$ and $0.001 \mathrm{yr}^{-1}$, respectively. On the contrary, post-correction annual maximum and minimum flow rates and the ratio of $\mathrm{Q}_{\max } / \mathrm{Q}_{\min }$ show trends of 0.13 and $0.04 \mathrm{~m}^{3}[?] \mathrm{s}^{-1}[?] \mathrm{yr}^{-1}$ and $-0.08 \mathrm{yr}^{-1}$, respectively.

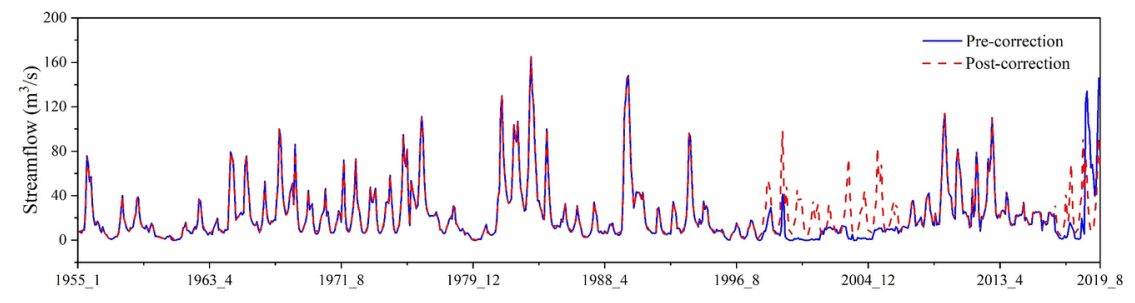

Fig. 4 Comparison of uncorrected and corrected streamflows of the Yellow River at the Huangheyan (HHY) Hydrological Station in the Headwater Area of the Yellow River on the northeastern Qinghai-Tibet Plateau, Southwest China during the period from January 1955 to August 2019

\subsection{Projection of future streamflow in the HAYR}

By employing the method of Elman Neural Network (ENN), the monthly YR streamflow in the HAYR is forecasted over the next 20 year. Two indicators (Root mean squared error (RMSE) in $\mathrm{m}^{3}[?] \mathrm{s}^{-1}$ and Coefficient of correlation, R) are employed to evaluate the performance of the trained ENN (Wang et al., 2019a). The result shows an RMSE of training data at $9.16 \mathrm{~m}^{3}[?] \mathrm{s}^{-1}$ and $\mathrm{R}$ at 0.94 , and an RMSE of testing data at $13.7 \mathrm{~m}^{3}[?] \mathrm{s}^{-1}$ and $\mathrm{R}$ at 0.79 . They indicate that the ENN-simulated monthly YR streamflow data 
fit well with the measured monthly YR streamflow data in the HAYR and the trained ENN can effectively simulate monthly streamflow in the HAYR (Fig. 5).

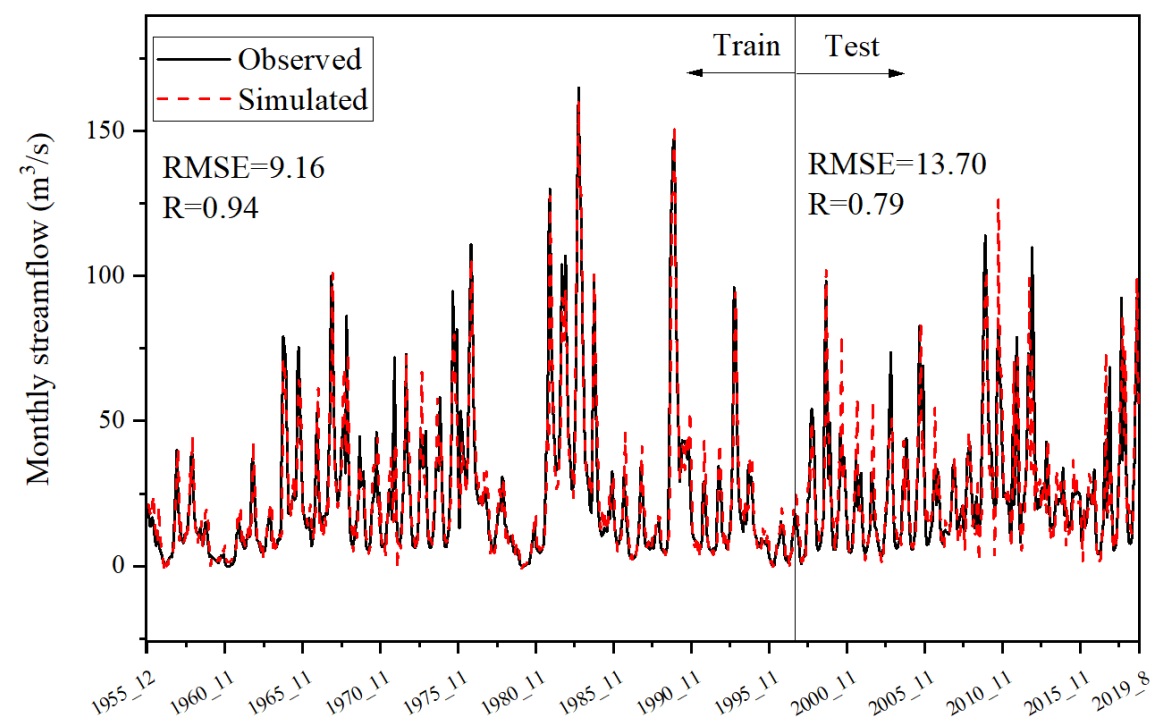

Fig. 5 Observed and simulated monthly streamflows of the Yellow River at the Huangheyan (HHY) Hydrological Station in the Headwater Area of the Yellow River on the northeastern Qinghai-Tibet Plateau, Southwest China during the period from December 1955 to August 2019

This trained ENN was then used for predicting the monthly, seasonal and annual YR streamflow in the HAYR over the next 20 years from January 2020 to December 2040. The forecasted result is shown in Fig. 6. Over the next 20 years, monthly, seasonal and annual YR streamflow in the HAYR show consistently increasing trends, yet to varied extents.

Compared to the increasing trends $\left(0.11 \mathrm{~m}^{3}[?] \mathrm{s}^{-1}[?] \mathrm{yr}^{-1}\right)$ of annual YR streamflow in the HAYR from 1955 to 2019 , more remarkable increasing trends $\left(0.42 \mathrm{~m}^{3}[?] \mathrm{s}^{-1}[?] \mathrm{yr}^{-1}\right)$ are predicted over the next 20 years in the HAYR.

Predicted winter flow of YR in the HAYR shows an increasing trend as $0.49 \mathrm{~m}^{3}[?] \mathrm{s}^{-1}[?] \mathrm{yr}^{-1}$, compared to the increasing trends from 1955 to $2019\left(0.08 \mathrm{~m}^{3}[?] \mathrm{s}^{-1}[?] \mathrm{yr}^{-1}\right)$ and multi-year average winter streamflow from 2020 to 2040 is predicted to be 1.2 times higher than that from 1955 to 2019.

Predicted spring streamflow shows a more sharply increasing trend over the next 20 years $\left(0.57 \mathrm{~m}^{3}\left[? \mathrm{~s}^{-1}[?] \mathrm{yr}^{-1}\right)\right.$ in comparison with that of $1955-2019\left(0.16 \mathrm{~m}^{3}[?] \mathrm{s}^{-1}[?] \mathrm{yr}^{-1}\right)$. Summer and autumn streamflow both show increasing trends of 0.28 and $0.18 \mathrm{~m}^{3}[?] \mathrm{s}^{-1}[?] \mathrm{yr}^{-1}(1955-2040)$, respectively, which are higher than those from 1955 to $2019\left(0.12 \mathrm{~m}^{3}[?] \mathrm{s}^{-1}[?] \mathrm{yr}^{-1}\right.$ and $0.16 \mathrm{~m}^{3}[?] \mathrm{s}^{-1}[?] \mathrm{yr}^{-1}$, respectively).

The predicted trends of annual maximum and minimum YR streamflow will be 0.66 and 0.22 $\mathrm{m}^{3}[?] \mathrm{s}^{-1}[?] \mathrm{yr}^{-1}$ respectively, which will be higher than those from 1955 to 2019 of 0.13 and $0.04 \mathrm{~m}^{3}[?] \mathrm{s}^{-1}[?] \mathrm{yr}^{-1}$. Predicted trends of the ratio of $\mathrm{Q}_{\mathrm{Max}} / \mathrm{Q}_{\mathrm{Min}}$ decreases at a rate of $-0.11 \mathrm{yr}^{-1}$ which is lower than that from $1955-2019$ of -0.08 [?] $\mathrm{yr}^{-1}$.

Taking into accounts of generally increasing trends of monthly, seasonal and annual YR streamflow, the HAYR will be stepping into a wetting period over the next 20 years. In contrast, a more evident decreasing trend of $\mathrm{Q}_{\mathrm{Max}} / \mathrm{Q}_{\mathrm{Min}}$ ratio implicates that permafrost degradation in the HAYR will keep on modifying the seasonal distributive patterns of YR streamflow and impact the subsurface hydrological processes in the HAYR during the next 20 years. 


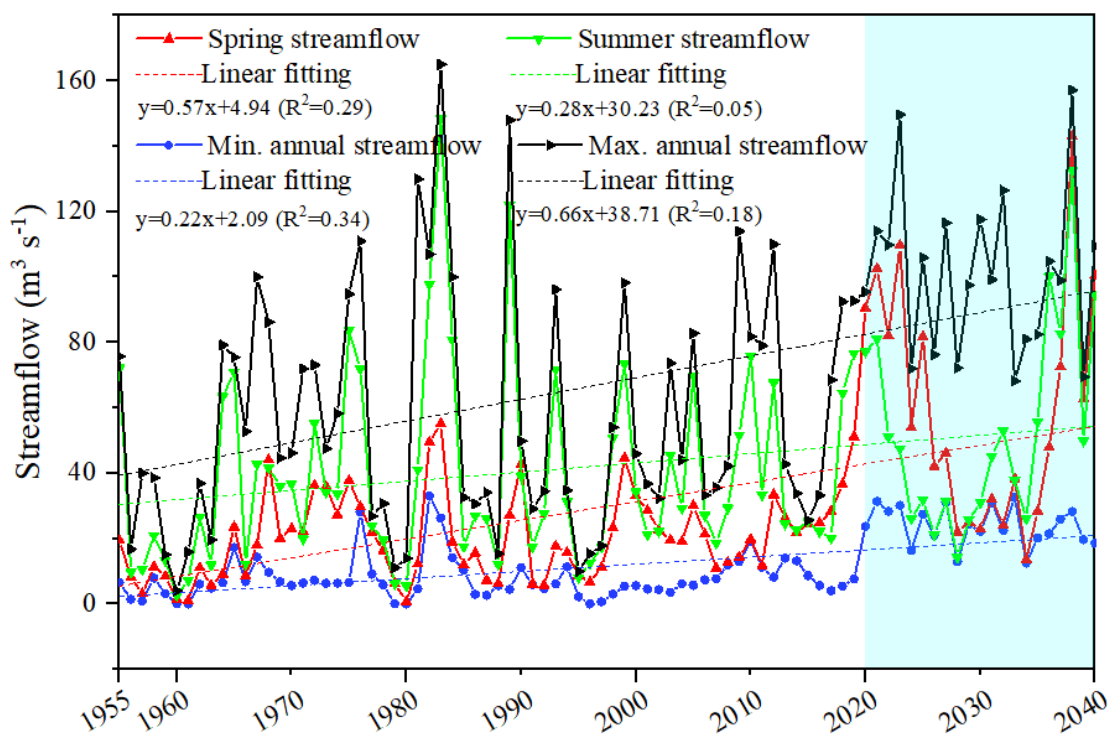

Fig. 6 Measured and predicted Yellow River streamflow in the HAYR from 1955 to 2040

Notes:

Flow data from 1955 to 2019 were measured at the HHY.

Data in green shadows are predicted annual maximum and minimum YR flows and summer and spring YR flows in the HAYR by using the trained Elman Neural Network (ENN) method.

\subsection{Discussions}

The presence of the FHHS dam has changed trends of monthly, seasonal and annual YR streamflow in the HAYR. Trends of winter baseflow was increasing at a rate of $0.08 \mathrm{~m}^{3}[?] \mathrm{s}^{-1}[?] \mathrm{yr}^{-1}$ during 1955-2019, and; annual minimum streamflow, at a rate of 0.04; However, the ratio of $\mathrm{Q}_{\mathrm{Max}} / \mathrm{Q}_{\mathrm{Min}}$ was decreasing at a rate of $-0.08 \mathrm{yr}^{-1}$ in comparison to the pre-correction trends as 0.07 and $-0.004 \mathrm{~m}^{3}[?] \mathrm{s}^{-1}[?] \mathrm{yr}^{-1}$ and $0.001 \mathrm{yr}^{-1}$, respectively.

On other QTP basins and northern/boreal permafrost regions, similar streamflow regimes have been widely reported. Wang et al. (2019b) analyzed the winter baseflow and annual minimum streamflow of the upper reach of the Hei'he basin (URHB) on the northeastern QTP and highlighted a notable increase of winter baseflow and annual minimum streamflow $\left(55 \%\right.$. and $64 \% \cdot \mathrm{yr}^{-1}$, respectively). Using hydrological model coupled with a Simultaneous Heat and Water (SHAW) model, Zhang et al. (2017) notes removal of permafrost module gain winter baseflow of the URHB by a factor of two to three. Song et al. (2019) examined streamflow patterns of two sub-catchments in the Yangtze River Basin and noted increasing trends of winter baseflow. On the basis of Gravity Recovery and Climate Experiment (GRACE) satellite data, Guo et al. (2016) highlight water storage on the QTP catchments has undergone an overall increase (2003-2012) and the most significant increase of change of water storage on the QTP is in continuous permafrost regions $(\mathrm{Xu}$ et al., 2016). In northeastern permafrost regions of China, decreasing trends of winter baseflow have also been frequently reported. Liu et al. (2003) examined a boosted winter flow (1958-1998) in a sub-catchment of northmost basin, Heilongjiang Basin, in China. Duan et al. (2017) addressed significantly positive trends of winter baseflow in two permafrost catchments in northern China. Ye et al. (2011) examined the streamflow regimes in the Lena catchments in the Eastern Siberia, Russia and found downward trends of $\mathrm{Q}_{\mathrm{Max}} / \mathrm{Q}_{\mathrm{Min}}$. Smith et al. (2007) investigated the minimum streamflow of 111 northern Eurasian catchments, revealing an overall pattern of increasing minimum streamflow. Lyon and Destouni (2010) investigated the changes in 
streamflow at sub-catchments in the Yukon River Basin across Arctic Alaska and NWT, Canada and relative increases in groundwater flow was observed.

Permafrost, ice-rich permafrost soils in particular, has low hydraulic connectivity, which can greatly restrain water infiltration to deeper soil strata (Ye et al., 2009; Bense et al., 2012; Walvoord and Kurylyk, 2016). Presence of permafrost will change water distribution in subsurface layers and seasonal distribution of streamflow (Woo et al., 2012; Kane et al., 2013; Walvoord and Kurylyk, 2016). With a degrading permafrost, the difference between summer stormflow and winter baseflow will be reduced and the ratio of $\mathrm{Q}_{\mathrm{Max}} / \mathrm{Q}_{\mathrm{Min}}$ will decline, flattening the annual hydrograph (Ye et al, 2012; Ma et al., 2019). Over the next two decades (2020$2040)$, the trends for annual minimum streamflow $\left(0.22 \mathrm{~m}^{3}[?] \mathrm{s}^{-1}[?] \mathrm{yr}^{-1}\right)$ and the ratio of $\mathrm{Q}_{\mathrm{Max}} / \mathrm{Q}_{\mathrm{Min}}(-0.11$ $\mathrm{yr}^{-1}$ ) have revealed that the degrading permafrost will further impact surface and subsurface hydrological processes and spatiotemporal distributive patterns of water resources in the HAYR.

The annual YR streamflow in the HAYR demonstrates an adversely upward trend as $0.11 \mathrm{~m}^{3}[?] \mathrm{s}^{-1}[?] \mathrm{yr}^{-1}$, compared to the insignificantly decreasing trend as $-0.009 \mathrm{~m}^{3}[?] \mathrm{s}^{-1}[?] \mathrm{yr}^{-1}$ before the flow correction and the annual YR streamflow in the HAYR is predicted to increases more significantly over the next 20 years $(0.19$ $\left.\mathrm{m}^{3}[?] \mathrm{s}^{-1}[?] \mathrm{yr}^{-1}\right)$. As reported by earlier studies, in most permafrost catchments on the QTP, such as the upstreams of the Yangtze, Mekong, Yarlung Tsangpo and Salween rivers, an increasing streamflow has been observed in recent decades (Cuo et al., 2014; Liu et al., 2018). Boosted precipitation (mainly snowfall from mid-autumn to next spring) and shrinking cryospheric components are the major drivers for upward trends of basin streamflow on the QTP (Liu et al., 2018; Tang et al., 2019). Modern glaciers cover an areal extent of 49,873-98,739 $\mathrm{km}^{2}$ with an ice storage of 4,561-7481 $\mathrm{km}^{3}$ on the QTP (Yao et al., 2013; Wang et al., 2019c). The HAYR, without the presence of modern glaciers, is extensively underlain by permafrost (86\%), of which ground-ice meltwater contributes $14.4 \%$ annual streamflow to the YR at HHY in the HAYR (Ma et al., 2019). Total ground ice in permafrost regions on the QTP is estimated as 9,528-12,700 $\mathrm{km}^{3}$ (Zhao et al., 2010, 2019; Cheng et al., 2019). Thus, under a wetting-warming climate trend in the future, a trend of generally boosted annual streamflow will be expected in permafrost or cryosphere dominated basins on the QTP (Zhao et al., 2019). A general increasing trend from instrumental record of streamflow to Arctic Oceans has been identified and it seems only more prominent in Eurasian rivers (Durocher et al., 2019). Eurasian Arctic catchments contribute $75 \%$ of the total terrestrial streamflow to the Arctic Ocean, Shiklomanov et al. (2013) noted a 7\% increase of streamflow over the period of 1939-1999, which was projected to be accelerating in the $21^{\text {st }}$ century. Thus, over much of both northern and plateau catchments, streamflow demonstrates consistently upward trends.

Corrected spring and autumn streamflow show increasing trends (0.16 and $0.16 \mathrm{~m}^{3}[?] \mathrm{s}^{-1}[?] \mathrm{yr}^{-1}$, respectively). In most northern/boreal basins, boosted spring streamflow has been found in the last decades (Yang et al., 2004; Ahmed et al., 2020). It has been suggested that the early snowmelt associated with climate warming during snowmelt period accounts for the boosted spring streamflow (Ye et al., 2003; Makarieva et al., 2019). Rising trends of autumn streamflow are not so widely reported as to the increasing trends of spring and winter streamflow, but they have also been noted in some studies (Caine, 2010; Makarieva et al., 2019; Kopysov and Erofeev, 2019) and explained as shifts of nival/pluvial precipitation due to climate warming and seasonal thawing of permafrost (Kopysov and Erofeev, 2019). The trend of summer streamflow is often reported as decreasing due to the lowered precipitation/evaporation ratio (e.g., Spence et al., 2011). The summer streamflow in the HAYR demonstrates a general trend of decrease (1961-2017) in some earlier studies, but shows a conversely increasing trends $\left(0.12 \mathrm{~m}^{3}[?] \mathrm{s}^{-1}[?] \mathrm{yr}^{-1}\right)$ when data is updated and corrected (1955-2019) in this paper.

\section{Conclusion}

1. Construction and operation of the hydropower station (FHHS) in the HAYR substantially causes the inter- and intra-annual YR streamflow variability in the HAYR. Construction of the dam has caused a 53.5\%-68.4\% reduction of annual YR streamflow (1998-2000) and a 71.8 \%-94.4\% reduction of annual YR streamflow in dry years (2003-2005) in the HAYR and the recent implementation of partial dam removal (September 2018) has boosted annual streamflow by $123 \%-210 \%$. Annual YR streamflow 
measured at HHY in the HAYR demonstrates insignificantly decreasing trend before correction and goes upwards after correction. Seasonal trends of YR streamflow in spring, summer, autumn and winter shows trends of $-0.04,-0.18,-0.03$ and $0.07 \mathrm{~m}^{3}[?] \mathrm{s}^{-1}[?] \mathrm{yr}^{-1}$ before correction; $0.16,0.12,0.16$ and $0.08 \mathrm{~m}^{3}[?] \mathrm{s}^{-1}[?] \mathrm{yr}^{-1}$ after correction.

2. Presence of the FHHS largely conceals the hydrological signals for permafrost degradation in the HAYR. Permafrost, played as a barrier to seepage of subsurface waters, alter subsurface hydrological processes and streamflow patterns. Winter baseflow will be boosted and the ratio of $\mathrm{Q}_{\mathrm{Max}} / \mathrm{Q}_{\mathrm{Min}}$ will decline. Post-correction trends of annual minimum streamflow, winter baseflows and the ratio of $\mathrm{Q}_{\mathrm{Max}} / \mathrm{Q}_{\mathrm{Min}}$ in the HAYR of 0.04 and $0.08 \mathrm{~m}^{3}[?] \mathrm{s}^{-1}[?] \mathrm{yr}^{-1}$ and $-0.08 \mathrm{yr}^{-1}$. In comparison to trends of pre-correction annual minimum streamflow, winter baseflow and the ratio of $\mathrm{Q}_{\mathrm{Max}} / \mathrm{Q}_{\mathrm{Min}}$ of -0.004 and $0.07 \mathrm{~m}^{3}[?] \mathrm{s}^{-1}[?] \mathrm{yr}^{-1}$ and $0.001 \mathrm{yr}^{-1}$, respectively, post-correction YR streamflow has evidenced an elevated annual minimum streamflow and winter baseflow and a declined ratio of $\mathrm{Q}_{\mathrm{Max}} / \mathrm{Q}_{\mathrm{Min}}$ (flattening hydrograph) induced by permafrost degradation. In the next 20 years, the e ratio of $\mathrm{Q}_{\mathrm{Max}} / \mathrm{Q}_{\mathrm{Min}}$ is projected to further decline. Permafrost degradation will continue to impact subsurface hydrological processes and YR flows in the HAYR.

3. The total YR streamflow in the HAYR shows a generally increasing trend $\left(0.11 \mathrm{~m}^{3}[?] \mathrm{s}^{-1}[?] \mathrm{yr}^{-1}\right)$ and over the next 20 years, will have a more prominent increasing trend $\left(0.42 \mathrm{~m}^{3}[?] \mathrm{s}^{-1}[?] \mathrm{yr}^{-1}\right)$. Together with a changing climate, a warm-wet HAYR is expected, as observed in other QTP and northern catchments. Boosted change trends of spring YR flow $\left(0.57 \mathrm{~m}^{3}[?] \mathrm{s}^{-1}[?] \mathrm{yr}^{-1}\right)$ and autumn YR flow $(0.22$ $\left.\mathrm{m}^{3}[?] \mathrm{s}^{-1}[?] \mathrm{yr}^{-1}\right)$ may reveal the advancing snow-melt season and postponing freeze-up and potential expansion of growing season. An expansion of growing season in the HAYR, will benefit plant growth and ecological restoration and a better ecological environment is expected in the HAYR. These hydrometeorological and ecological trends in the HAYR may also help ensure ecological safety and water supply in local communities and the downstream YR basins.

\section{Acknowledgement}

This work was supported by the Chinese Academy of Sciences (CAS) Strategic Priority Research Program "Changing permafrost hydrology in the Qilian Mountains and the Source Area of the Yellow River and its impacts on water supplies and security " (Grant No. XDA20100103), Ministry of Science and Technology of China Key R\&D Program (Grant No. 2017YFC0405704) "Research and development of techniques and equipment for online monitoring of essential hydrological elements in cold regions ", and CAS Overseas Professorship of Victor F Bense at the former Cold and Arid Regions Environmental and Engineering Research Institute (now renamed to Northwest Institute of Eco-Environment and Resources), CAS during 2013-2016.

\section{Data Availability Statement}

The data that support the findings of this study are available in the following links (extraction code: uc71): https://pan.baidu.com/s/1fam6eb64cu6baXh8J9iuMw.

\section{References}

Adam, J.C., Haddeland, I., Su F., \& Lettenmaier, D.P. (2007). Simulation of reservoir influences on annual and seasonal streamflow changes for the Lena, Yenisei, and Ob' rivers. Journal of Geophysical Research, 112: D24114. http://doi.org/10.1029/2007JD008525.

Ahmed, R., Prowse, T., Dibike Y., Bonsal, B., \& O’Neil, H. (2020). Recent trends in freshwater influx to the Arctic Ocean from four major Arctic-draining rivers. Water, 12(4): 1-13.

Bense, V.F., Kooi, H., Ferguson, G., \& Read T. (2012). Permafrost degradation as a control on hydrogeological regime shifts in a warming climate. Journal of Geophysical Research-Earth, 117: F03036. http://doi.org/10.1029/2011jf002143

Birkundavyi, S., Labib, R., Trung, H.T., \& Rousselle J. (2002). Perfromance of neural networks in daily streamflow forecasting. Journal of Hydrological Engineering, 7: 392. http://org.doi/ 10.1061/(ASCE)10840699(2002)7:5(392). 
Brierley, G.J., Li, X.L., Cullum, C., \& Gao, J. (2016). Landscape and ecosystem diversity in the Yellow River Source Zone. In Landscape and Ecosystem Diversity, Dynamics and Management in the Yellow River Source Zone, Brierley, G.J., Li, X., Cullum, C., \& Gao, J., (ed.). Springer Geography: Switzerland, pp. $1-34$.

Bring, A., \& Destouni, G. (2014). Arctic climate and water change: Model and observation relevance for assessment and adaptation. Survey in Geophysics, 35: 853-877.

Bring, A., Shiklomanov, A., \& Lammers, R.B. (2017). Pan-Arctic river discharge: Prioritizing monitoring of future climate change hot spots. Earth's Future, 5: 72-92.

Caine N. (2010). Recent hydrologic change in a Colorado alpine basin: an indicator of permafrost thaw? Annals of Glaciology, 51(56): 130-134.

Campbell, T.K.F., Lantz, T.C., Fraser, R.H., \& Hogan, D. (2020). High Arctic vegetation change mediated by hydrological conditions. Ecosystems 23. http://doi.org/ 10.1007/s10021-020-00506-7.

Chai, Y., Li, Y., Yang Y., Zhu B., Li S., Xu C., \& Liu C. (2019). Influence of climate variability and reservoir operation on streamflow in the Yangtze River. Scientific Report, 9: 5060. http://doi.org/ 0.1038/s41598019-41583-6.

Cheng, G., \& Jin, H. (2012).Permafrost and groundwater on the Qinghai-Tibet Plateau and in northeast China. Hydrogeology Journal, 21(1): 5-23.

Cheng, G., Zhao, L., Li, R., Wu, X., Sheng, Y., Hu, G., .. Wu, Q. (2019). Characteristics, changes and impacts of permafrsot on Qinghai-Tibet Plateau. Chinese Science Bulletin, 64: 2783-2795.

Ministry of Water Resources of the People's Republic of China (MWRPRC), (2008-2017). Bulletin of river sediment in China.http://www.mwr.gov.cn/sj (In Chinese)

Cuo, L., Zhang, Y.X., Zhu, F.X., \& Liang, L.Q. (2014). Characteristics and changes of streamflow on the Tibetan Plateau: A review. Journal of Hydrology: Regional Studies, 2: 49-68.

Dolling, O.R., \& Varas, E.A. (2002). Artificial neural networks for streamflow prediction. Journal of Hydraulic Research, 40: 547-554.

Duan, L., Man, X., Kurylyk, B. L. \& Cai, T. (2017). Increasing Winter Baseflow in Response to Permafrost Thaw and Precipitation Regime Shifts in Northeastern China. Water, 9(25): 1-15.

Durocher, M., Requena, A. I., Burn, D., \& Pellerin, J. (2019). Analysis of trends in annual streamflow to the Arctic Ocean. Hydrological Processes, 33: 1143-1151.

Ge, S., Yang, D., \& Kane, D.L. (2013). Yukon River Basin long-term (1977-2006) hydrologic and climatic analysis. Hydrological Processes, 27: 2475-2484.

Guo, J., Mu, D., Liu, X., Yan, H., Sun, Z., \& Guo B. (2016). Water storage changes over the Tibetan Plateau revealed by GRACE mission. Acta Geophysica, 64: 463-476.

Haine, T.W.N., Curry, B., Gerdes, R., Hansen, E., Karcher, M., Lee, C.,... Woodgate, R. (2015). Arctic freshwater export: Status, mechanisms, and prospects. Global and Planetary Change. 125: 13-35.

Han, T., Pu, H., Cheng, P., \& Jiao, K. (2016). Hydrological effects of alpine permafrost in the headwaters of the Urumqi River, Tianshan Mountains. Sciences in Cold and Arid Regions 8: 241-249.

Hernandez-Henriquez, M.A., Mlynowski, T.J., \& Dery, S.J. (2010). Reconstructing the natural streamflow of a regulated river: A case study of La Grande Riviere, Quebec, Canada. Canadian Water Resources Journal, 35: 301-316.

Hu, Y., \& Hwang, J. (2002). Application of artificial neural networks to time series prediction. In Handbook of Neural Network Signal Processing, Hu, Y., Hwang, J., (eds). CRC Press: Florida, pp. 249-266. 
Jin, H., He, R., Cheng, G., Wu, Q., Wang, S., Lu, L., \& Chang, X. (2009). Changes in frozen ground in the Source Area of the Yellow River on the Qinghai-Tibet Plateau, China, and their eco-environmental impacts. Environmental Research Letters, 4: 045206. http://doi.org/ 10.1088/1748-9326/4/4/045206.

Jin, H., Luo, D., Wang, S., Lu, L., \& Wu, J. (2011). Spatialtemporal variability of permafrost degradation on the Qinghai-Tibet Plateau. Science in Cold Arid Regions, 3: 0281-0305.

Jin, H.J., Jin, X.Y., He, R.X., Luo, D.L., Chang X.L., Wang, S.L., \& Harris, S.A. (2019). Evolution of permafrost in China during the last 20 ka. Science China, Series D: Earth Sciences, 62: 1207-1223.

Kane, D.L., Yoshikawa, K., \& McNamara, J.P. (2013). Regional groundwater flow in an area mapped as continuous permafrost, NE Alaska (USA). Hydrogeology Journal, 21: 41-52.

Kopysov, S., \& Erofeev, A. (2019). The influences of climate on runoff: a case study of four catchments in Western Siberia. Geographical Foundations, 381: 012046. http://org.doi/10.1088/1755-1315/381/1/012046.

Kurylyk, B.L., Hayashi, M., Quinton, W.L., McKenzie, J.M., \& Voss, C.I. (2016). Influence of vertical and lateral heat transfer on permafrost thaw, peatland landscape transition, and groundwater flow. Water Resource Research, 52: 1286-1305.

Li, J., Sheng, Y., Wu, J., Feng, Z., Hu, X., Zhang, X. (2016). Landform-related permafrost characteristics in the source area of the Yellow River, eastern Qinghai-Tibet Plateau. Geomorphology, 269: 104-111.

Li, Z., Liu, X., Niu, T., \& De, K. (2015). Ecological restoration and its effects on a rergional climate: the Source Region of the Yellow River, China. Environmental Science \& Technology, 49: 5897-5904.

Liu, J., Hayakawa, N., Lu, M., Dong, S., \& Yuan, J. (2003). Winter Streamflow, Ground Temperature and Active-Layer Thickness in Northeast China. Permafrost and Periglacial Processes, 14: 11-18.

Liu, J., Duan, Y., Hao, G., Ge, X., \& Sun, H. (2014). Evolutionary history and underlying adaptation of alpine plants on the Qinghai-Tibet Plateau. Journal of Systematics and Evolution, 52(3): 241-249.

Liu, W., Sun, F., Li, Y., Zhang, G., Sang, Y., Lim, W.H.,...Bai, P. (2018). Investigating water budget dynamics in 18 river basins across the Tibetan Plateau through multiple datasets. Hydrology and Earth System Sciences, 22(1): 351-371.

Luo, D., Jin, H., Lin, L., He, R., Yang, S., \& Chang, X. (2012). Progress in permafrost temperature and thickness in the source area of the Huanghe River. Scientia Geographica Sinica, 32: 898-904 (in Chinese)

Luo, D., Jin H., Marchenko, S., \& Romanovsky, V. (2014). Distribution and changes of active layer thickness (ALT) and soil temperature (TTOP) in the source area of the Yellow River using the GIPL model. Science China: Earth Science, 57: 1834-1845.

Luo, D., Jin, H., Jin, X., He, R. X., Li, X., Muskett, R., Marchenko, S., \& Romanovsky, V. (2018). Elevationdependent thermal regime and dynamics of frozen ground in the Bayan Har Mountains, northeastern QinghaiTibet Plateau, southwest China. Permafrost and Periglacial Processes, 29: 257-270.

Luo, D., Liu, L., Jin, H. J., Wang X., \& Chen F. (2020). Characteristics of ground surface temperature at Chalaping in the Source Area of the Yellow River, northeast Tibetan Plateau, Agricultural and Forestry Meteorology, 281: 10819. http://org.doi/10.1016/j.agrformet.2019.107819.

Lyon S W, \& Destouni G. (2010). Changes in Catchment-Scale Recession Flow Properties in Response to Permafrost Thawing in the Yukon River Basin. International Journal of Climatology, 30: 2138-2145.

Ma, Q., Jin, H., Bense, F. V., Luo, D., Marchenko, S., Harris, A., Lan, Y. (2019). Impacts of degrading permafrost on streamflow in the source area of Yellow River on the Qinghai-Tibet Plateau, China. Advance in Climate Change Research. 10(4): 225-239. 
Makarieva, O., Nesterova, N., Post, D. A.. Sherstyukov, A. \& Lebedeva, L. (2019). Warming temperatures are impacting the hydrometeorological regime of Russian rivers in the zone of continuous permafrost. The Cryosphere, 13: 1635-1659.

Prowse, T.D., Wrona, F.J., Reist, J.D., Gibson, J.J., Hobbie, J.E., Le'vesque, L.M.J., \& Vincent, W.F. (2006). Climate change effects on hydroecology of Arctic freshwater ecosystems. Ambio, 35: 347-358.

Qinghai Institute of Geological Survey (QIGS). (2000). The Geological survey research report about ecoenviornment in the Source Area of the Yellow River. Qinghai Institute of Geological Survey (QIGS), Qinghai, China.

Qiu, J. (2014). Thawing permafrost reduces river runoff? Available online: https://www.nature.com/news/thawing-permafrost -reduces-river-runoff-1.9749 [accessed 06 January 2012].

Sahoo, A., Samantaray, S., \& Ghose, D.K. (2019). Stream flow forecasting in Mahanadi River Basin using artificial neural networks. Procedia Computer Science, 157: 168-174.

Searcy, J.K., \& Hardison, C.H. (1960) Double-mass curves. InManual of Hydrology: Part I: General SurfaceWater Techniques, U. S. Geological Survey, (eds). U. S. Government Printing Office: Washington, D. C., pp. 13-59.

Sequoira, H., \& Luna, I. (2019). Performance comparison of feedforward neural networks applied to streamflow series forecasting. Mathematics in Engineering, Science and Aerospace, 10: 41-53.

Sheng, Y., Ma, S., Cao, W., \& Wu, J. (2020). Spatiotemporal changes of permafrost in the Headwater Area of the Yellow River under a changing climate. Land Degradation and Development, 31: 133-152.

Shiklomanov, A.I., Lammers, R.B., Lettenmaier, D.P., Polischuk, Y.M., Savichev, O.G., Smith, L.C., \& Chernokulsky, A.V. (2013). Hydrological changes: historical analysis, contemporary status, and future projections. In Regional Environmental Changes in Siberia and Their Global Consequences ; Groisman, P.Y., Gutman, G., (eds). Springer Netherlands: Dordrecht, the Netherlands, pp.111-154.

Smith, L., Pavelsky, T., MacDonald, G., Shiklomanov, A., \& Lammers, R. (2007). Rising minimum daily flows in northern Eurasian rivers: A growing influence of groundwater in the high-latitude hydrologic cycle. Journal of Geophysical Research-Biogeosciences, 112: G04S47. http://doi.org/10.1029/2006JG000327

Song, C, Wang, G, Mao, T. Dai, J. \& Yang, D. (2019). Linkage between permafrost distribution and river runoff changes across the Arctic and the Tibetan Plateau. Science China, Series D: Earth Sciences, 62: 1-11.

Spence, C., Kokelj, S. V., Ehsanzadeh, E., (2011). Precipitation trends contribute to streamflow regime shifts in northern Canada. In:Cold Regions Hydrology in a Changing Climate, Yang, D., Marsh, P., \& Gelfan, A. (eds). IAHS: Melbourne, Australia.

Stuefer, S., Yang, D., \& Shiklomanov, A. (2011). Effect of streamflow regulation on mean annual discharge variability of the Yenisei River. InCold Regions Hydrology in a Changing Climate, Yang, D., Marsh, P., \& Gelfan, A. (eds). IAHS: Melbourne, Australia.

Tang, Q., Lan, C., Su, F., Liu, X., Sun, H., Ding, J... Chen, D. (2019). Streamflow change on the QinghaiTibet Plateau and its impacts. Chinese Science Bulletin, 64(27): 2807-2821. (In Chinese)

Walvoord, M.A., \& Kurylyk, B.L. (2016). Hydrologic impacts of thawing permafrost-A review. Vadose Zone Journal, 15: 1-20.

Wang, G., Wang, Y., Li, Y., \& Cheng, H. (2007). Influences of alpine ecosystem responses to climatic change on soil properties on the Qinghai-Tibet Plateau, China. Catena, 70: 506-514.

Wang, S., Sheng, Y., Li, J., Wu, J., Cao, W., \& Ma, S. (2018). An estimation of ground ice volumes in permafrost layers in Northeastern Qinghai-Tibet Plateau, China. Chinese Geographical Science, 28: 61-73. 
Wang, L., Li, X., Ma, C., \& Bai, Y. (2019a). Improving the prediction accuracy of monthly streamflow using a datadriven model based on a double-processing strategy. Journal of Hydrology, 573: 733-745.

Wang, X., Chen, R., Liu, G, Han, C, Yang, Y., Song, Y., \& Guo, S. (2019b). Response of low flows under climate warming in high-altitude permafrost regions in western China. Hydrological Processes, 33: 66-75.

Wang, N., Yao, T., Xu, Q., Chen, A., \& Wang, W. (2019c). Spatial patterns, trend and influence of glacier change in Tibetan Plateau and surroudings after global warming. Bulletin of Chinese Academy of Sciences, 34(11),1220-1232. (In Chinese)

Woo, M. K. (2012). Permafrost hydrology. Springer Science \& Business Media, Heidelberg, Germany.

Xu, M., Kang, S., Zhao, Q., \& Li, J. (2016). Terrestrial water storage changes of permafrost in the ThreeRiver Source Region of the Tibetan Plateau, China. Advance in Meteorology, 1: 1-13. http://org.doi/10. $1155 / 2016 / 4364738$

Xu, R., Hu, H., Tian, F., Li C., \& Khan, M. Y. A. (2019). Projected climate change impacts on future streamflow of the Yarlung Tsangpo-Brahmaputra River. Global and Planetary Change, 175: 144-159.

Yang, D., Ye, B., \& Kane, D.L. (2004). Streamflow changes over Siberian Yenisei River Basin. Journal of Hydrology, 296: 59-80.

Yao, T., Qin, D. H, Shen Y., Zhao, L., Wang, N., \& Lu, X. (2013). Cryospheric changes and their impacts on regional water cycle and ecological conditions in the Qinghai-Tibetan Plateau. Chinese Journal of Nature, 35(3): 179-186. (In Chinese)

Ye, B., Yang, D., \& Kane, D. L. (2003). Changes in Lena River streamflow hydrology: Human impacts versus natural variations. Water Resources Research, 39(7): 1200. http://org.doi/10.1029/2003wr001991

Ye, B., Yang, D., Zhang, Z., \& Kane, D. L. (2009). Variation of hydrological regime with permafrost coverage over Lena Basin in Siberia. Jounal of Geophysical Research, 114: D07102. http://doi.org/ 10.1029/2008JD010537

Ye, B., Yang, D., Zhang, T., Zhang, Y., \& Zhou, Z. (2011) Hydrological process change with air temperature over the Lena Basin in Siberia. In Proceedings of Cold Regions Hydrology in a Changing Climate, International Symposium H02 held during IUGG2011 at Melbourne, Australia, July 2011.

Ye, B., Ding, Y., Jiao, K., Shen, Y., \& Zhang, J. (2012). The response of river discharge to climate warming in cold region over China. Quaternary Sciences, 32: 103-110. (In Chinese)

Zeng, F., Collatz, G.J., Pinzon, J.E., \& Ivanoff, A. (2013). Evaluating and Quantifying the Climate-Driven Interannual Variability in Global Inventory Modeling and Mapping Studies (GIMMS) Normalized Difference Vegetation Index (NDVI3g) at Global Scales. Remote Sensing, 5(8): 3918-3950.

Zhang, S., Jia, S., Liu, C., Cao, W., Hao, F., Liu, J., \& Yan, H. (2004). Study on the changes of water cycle and its impacts in the source region of the Yellow River. Science in China, Series E: Engineering \& Materials Science.: 142-151.

Zhang, Y., Cheng, G., Li, X. Jin, H., Yang, D., Flerchinger, G. N., ...Liang, J. (2017). Influences of Frozen Ground and Climate Change on Hydrological Processes in an Alpine Watershed: A Case Study in the Upstream Area of the Hei'he River, Northwest China. Permafrost and Periglacial Processes, 28: 420-432.

Zhang, Y., Zheng, H., Herron, N., Liu, X., Wang, Z., Chiew, F.H.S., \& Parajka, J. (2019). A framework estimating cumulative impact of damming on downstream water availability. Jounal of Hydrology, 575: $612-627$.

Zhao, G., Li, E., Mu, X., Wen, Z., Rayburg, S., \& Tian, P. (2015). Changing trends and regime shift of streamflow in the Yellow River basin. Stochastic Environmental Research \& Risk Assessment, 29(5): 1331-1343. 
Zhao, L., Ding, Y., Liu, G., Wang, S., \& Jin, H. (2010). Estimates of the Reserves of Ground Ice in Permafrost Regions on the Tibetan Plateau. Journal of Glaciology and Geocryology, 22(2): 106-112. (In Chinese)

Zhao, L., Hu, G., Zou, D., Wu, X., Ma, L., Sun, Z., \&,... Liu, S. (2019). Permafrost Changes and Its Effects on Hydrological Processes on Qinghai-Tibet Plateau. Bulletin of Chinese Academy of Sciences, 34(11): 1223-1246.

Zheng, G., Yang, Y., Yang, D., Dafflon, B., Lei, H., \& Yang, H. (2019). Satellite-based simulation of soil freezing/thawing processes in the northeast Tibetan Plateau. Remote Sensing of Environment, 231: 11269. http://doi.org/ 10.1016/j.rse.2019.111269 